\title{
Postural Discomfort and Musculoskeletal Disorders among the Agricultural Workers in Faizabad District
}

\author{
Mohini ${ }^{1}$, U.V. Kiran ${ }^{2 *}$, Santoshi Kumari ${ }^{3}$ and Vishal Sharma ${ }^{4}$ \\ 'M.Sc. Student, Department of Human Development and Family Studies, School for Home Sciences, Babasaheb Bhimrao \\ Ambedkar University, Vidya Vihar, Raibareli Road, Lucknow - 226025, Uttar Pradesh, India; mohinitiwari969@gmail.com \\ 2Professor, Department of Human Development and Family Studies, School for Home Sciences, Babasaheb Bhimrao \\ Ambedkar University, Vidya Vihar, Raibareli Road, Lucknow - 226025, Uttar Pradesh, India; druvkiran@gmail.com \\ ${ }^{3}$ Research Scholar, Department of Human Development and Family Studies, School for Home Sciences, Babasaheb Bhimrao \\ Ambedkar University, Vidya Vihar, Raibareli Road, Lucknow - 226025, Uttar Pradesh, India; tosibhu@gmail.com \\ ${ }^{4}$ Assistant Professor, University Institute of Media Studies, Chandigarh University, Ludhiana - Chandigarh State Hwy, \\ Chandigarh - 140413, Punjab, India
}

\begin{abstract}
Background: Farming has been considered a physically demanding and associated with high risk occupation for musculoskeletal disorders. Agricultural workers have to adapt different postures while working in the fields, e.g. standing, bending, sitting, kneeling, raising hand, etc. They work for long duration in awkward postures, due to which they have to face a lot of postural discomforts. They go through a lot of physical hazards, and sometimes they have to face severe pain. Aim: The present study was conducted to find out the musculoskeletal disorders and postural discomfort among the agricultural workers while working in the fields. Materials and Methods: Present study was conducted on 150 agricultural workers. The sample was randomly selected in the Balramau area of Faizabad district. A self-structured interview schedule and the postural discomfort scale developed by Corlett and Bishop in (1976) were used for data collection. Result: The study revealed that maximum pain was felt in the upper back, upper arms, mid-back, lower arms, lower back, and buttocks. Female agricultural workers felt more pain as compared to male agricultural workers. Conclusion: Agricultural workers face lot of pain in different body parts. Proper training program and information about musculoskeletal disorders symptoms should be given to agricultural workers so that they can get help in identifying the symptoms. Training programmers to agricultural workers in adopting right postures to minimise the stress also need to be conducted.
\end{abstract}

Keywords: Agricultural Workers, Musculoskeletal Disorders, Postural Discomfort, Working Postures

\section{Introduction}

Agriculture is one of the most risky sectors within the working world and farmworkers are exposed to a variety of workrelated factors, which may affect their protection and health ${ }^{1}$. Farming can occurrence Musculo-Skeletal Disorders (MSDs) and so the common reasons for this are related to an important workload, repetitious vehement movements, and poor working postures ${ }^{2}$. Farming could be a physically hard work and this places farmworkers at possible risk of musculoskeletal disorders like Osteoarthritis of the hip and knee, Low Back Pain, neck and upper limb complaints, and Hand-Arm Vibration Syndrome ${ }^{3}$. Farming has been considered a high- dangerous for musculoskeletal disorders ${ }^{4}$. Farming as job, had some exertion or work tasks which are resounding physical tasks and take high standing of custom-made labour in farming occupation, which might increase risk of MSD's among agricultural workers $^{5}$. MSD's are defined as a group of disorders that affect the musculoskeletal system including the nerves, tendons, muscles, and supporting structures like intervertebral discs ${ }^{6}$. Musculoskeletal disorders are injuries or strain that affect the natural body's movements or musculoskeletal system, including the joints, ligaments, muscles, nerves, tendons and structures that support branches, neck and back ${ }^{16}$. They're the foremost common reason forward divide impending pain and disability, and are presently reported to be affecting countless people around the world ${ }^{7}$. It has been suggested that people have varying understandings about their musculoskeletal problem and understandings about disorder may touch health consequences similar as pain and disability directly

*Author for correspondence 
or edgeways by their effect on shifting ${ }^{15}$. Musculoskeletal complications (MSD's) are characterized as multi factorial. Findings of exploration have connected physical, psychosocial/ organizational, and individual occupational 'proximity factors' for the event of work-related musculoskeletal complications (MSDS) $)^{8}$. Ordinarily, musculoskeletal health outcomes for agronomists and farmworkers are classified into two different Species acute injuries and musculoskeletal disorders that result from incremental trauma. Acute injuries result from just once trauma like slips and falls, kicks by critters, cuts, and tears, and other single event exposures. On the other hand, MSD's are incremental in nature, developing from repeated exposures to a stressor?. Further to their physical things, MSD's affect the psychosocial status of people and impact their families and care takers ${ }^{4}$. MSD's also can transpire as a consequence of natural pathological processes ${ }^{10}$. These induce the worker to specific postures, movements, and force-pains, constituting a certain ranking of internal physical load. A high internal physical load may effectuate short term and long-term musculoskeletal symptoms. These factors include the work and frequentness of shifting of different body region, like forceful sweats, non-neutral body postures, and vibration ${ }^{14}$. Multiplex studies have shown that low reverse pain is that the commonest musculoskeletal fevers among farmers. In progressive countries, the 1- while frequentness rate of among tillers was 47 in Sweden, 23 in Finland, and 37 within the US Notwithstanding, in developing countries, the speed was much progressive especially in South West Nigeria, 72 and China, $64^{11}$. Due to the character of agriculture, farmers are at particular risk of developing musculoskeletal disorders. Farming exertion are influencing in awkward body postures including leaning, kneeling, crawling, bending, twisting to 1 side, lifting and carrying heavy loads, repeater stirrings which will lead to physical stress and traumatic injuries ${ }^{12}$. According to the 2010 data of International Labor Organization (ILO), around 160 million work-related disorders per period come about around the world, in which Work-related MusculoSkeletal conditions (WMSDs) have a prominent job in terms of occupational health and also economics ${ }^{13}$.

The musculoskeletal disorders faced by the agricultural workers and assess the postural discomfort while working in the field.

\section{Materials and Methods}

\subsection{Sample}

To carry out this research, the sample was selected from the Faizabad district. From the Faizabad district one block was selected randomly, and three villages were selected using multistage random sampling technique. The sample size was 150 , of which 76 were female and 74 were male agricultural workers.

\subsection{Tool Used}

A self-structured interview schedule and the postural discomfort scale developed by Corlett and Bishop in (1976) were used to carry out the present study. ${ }^{17}$

\subsection{Data Collection}

Interview method was used for gathering information from agricultural workers. 150 agricultural workers who had agreed to provide the information were selected. While collecting the data, all the rules and instructions given by the government for covid-19 were followed. Prior to data collection, permission was taken from the agricultural workers and the data was collected by visiting the field at their specified place where they were comfortable, and visiting their home when they were free.

\subsection{Statistical Analysis}

The data was coded and analyzed using IBM SPSS 20.0 Version. The levels of musculoskeletal pain in different body parts were calculated with the help of mean, standard deviation and the significance was tested using $t$ test and ANOVA.

\section{Results and Discussion}

\subsection{Age-wise Distribution}

The age group (20-30 years) proportion of male and female agricultural workers were $22.9 \%$ and $13.1 \%$ respectively. $20.2 \%$ of the male agricultural workers were in the age group of 30-40 while $25 \%$ of the female agricultural workers were in the age group of 30-40 years (Table 1).

Table 1. Age-wise distribution

\begin{tabular}{|c|c|c|c|}
\hline $\begin{array}{c}\text { Sl. } \\
\text { No. }\end{array}$ & $\begin{array}{c}\text { Age } \\
\text { (In years) }\end{array}$ & $\begin{array}{c}\text { Male } \\
(\mathbf{N = 7 4 )}\end{array}$ & $\begin{array}{c}\text { Female } \\
(\mathbf{N = 7 6 )}\end{array}$ \\
\hline 1. & $20-30$ & $17(22.9 \%)$ & $10(13.1 \%)$ \\
\hline 2. & $30-40$ & $15(20.2 \%)$ & $19(25 \%)$ \\
\hline 3. & $40-50$ & $19(25.6 \%)$ & $18(23.6 \%)$ \\
\hline 4. & $50-60$ & $10(13.5 \%)$ & $7(9.2 \%)$ \\
\hline 5 & 60 above & $13(17.5 \%)$ & $22(28.9 \%)$ \\
\hline
\end{tabular}

(Figures in parenthesis indicate percentages)

$25.6 \%$ male and $23.6 \%$ female agricultural workers belonged to the age group of $40-50$ years. $13.5 \%$ male agricultural workers and $9.2 \%$ female agricultural workers further come 
under the age group of 50-60 years. 28.9\% female agricultural workers and $17.5 \%$ male agricultural workers were found to be in the age group of 60 above.

\subsection{Working Hours}

Majority (62.1\%) of male agricultural workers worked for 6-8 hours, $21.0 \%$ of female agricultural workers worked for 6-8 hours a day. $61.8 \%$ of female agricultural workers worked for 8-10 hours, $37.8 \%$ of male agricultural workers worked 6-8 hours a day (Table 2).

Table 2. Working hours

\begin{tabular}{|l|c|c|c|}
\hline Sl. No. & Working hours & $\begin{array}{c}\text { Male } \\
\mathbf{N}=\mathbf{7 4}\end{array}$ & $\begin{array}{c}\text { Female } \\
\mathbf{N}=\mathbf{7 6}\end{array}$ \\
\hline 1. & $6-8$ & $46(62.1 \%)$ & $16(21.0 \%)$ \\
\hline 2. & $8-10$ & $28(37.8 \%)$ & $47(61.8 \%)$ \\
\hline 3. & $10-12$ & $0(0 \%)$ & $13(17.1 \%)$ \\
\hline
\end{tabular}

(Figures in parenthesis indicate percentages)

The data in the above clearly indicates maximum participation of female work force in farm work. $61.8 \%$ of females work for 8-10 hours, whereas only $37.8 \%$ of male farmers work for 8-10 hours. None of the male farmers work for $10-12$ hours whereas $17.1 \%$ of the female farmers work for 10-12 hours.

\subsection{Use of Safety Instruments}

$6.7 \%$ of male agricultural workers and $1.3 \%$ of female agricultural workers used hand gloves while doing their fieldwork. Most of the male (81.0\%) and female (72.3\%) agricultural workers used to wear long sleeve dresses for safety purposes while working in the field (Table 3).

Table 3. Use of safety instruments

\begin{tabular}{|l|c|c|c|}
\hline Sl. No. & $\begin{array}{c}\text { Safety } \\
\text { instruments }\end{array}$ & Male & Female \\
\hline 1. & Hand gloves & $5(6.7 \%)$ & $1(1.3 \%)$ \\
\hline 2. & Long-sleeve dress & $60(81.0 \%)$ & $55(72.3 \%)$ \\
\hline 3. & Shoes & $25(33.7 \%)$ & $24(31.5 \%)$ \\
\hline 4. & Face mask & $10(13.5 \%)$ & $6(7.8 \%)$ \\
\hline 5. & Sleeper & $26(35.1 \%)$ & $22(28.9 \%)$ \\
\hline
\end{tabular}

(Figures in parenthesis indicate percentages)

$33.7 \%$ of male respondents used shoes in the field. Similarly, $31.5 \%$ of female agricultural workers also used shoes while working in the field activities. A very small number of female (7.8\%) and male (13.5\%) agricultural workers had masks for safety. $35.1 \%$ of male agricultural workers and $28.9 \%$ of female agricultural workers worked with slippers in the field.

\subsection{Postures Adopted}

Majority (94.5\%) of male and female (98.6\%) agricultural workers worked in standing postures when they work on the farm. Major proportion (97.2\%) of male agricultural workers worked in the bending position, $100 \%$ of female agricultural workers used the bending position while working in the field (Table 4).

Table 4. Postures adopted

\begin{tabular}{|l|c|c|c|}
\hline Sl. No. & $\begin{array}{c}\text { Working } \\
\text { postures }\end{array}$ & Male & Female \\
\hline 1. & Standing & $70(94.5 \%)$ & $75(98.6 \%)$ \\
\hline 2. & Bending & $72(97.2 \%)$ & $76(100 \%)$ \\
\hline 3. & Sitting & $74(100 \%)$ & $76(100 \%)$ \\
\hline 4. & Kneeling & $25(33.3 \%)$ & $38(50 \%)$ \\
\hline 5. & $\begin{array}{c}\text { Sometimes } \\
\text { raising hands }\end{array}$ & $42(56.7 \%)$ & $45(59.2 \%)$ \\
\hline
\end{tabular}

(Figures in parenthesis indicate percentages)

Male and female agricultural workers used 100\% sitting postures, while doing their farm in the field. $33.3 \%$ of male agricultural workers worked in the field using the kneeling position whereas $50 \%$ of female agricultural workers used kneeling postures during working in the field. $56.7 \%$ of the male agricultural workers and $59.2 \%$ of the female agricultural workers worked in the fields with their hands raised.

\subsection{Musculoskeletal Disorders}

Problems due to musculoskeletal disorders are presented in Table 5. The table depicts that the maximum Musculoskeletal Disorders was felt by female agricultural workers in comparison to male agricultural workers. As seen from the table, female agricultural workers who do agriculture work had more pain in the neck and shoulders as compared to male agricultural workers. It is also clear that female agricultural workers had more Musculoskeletal Disorders in the upper back, upper arms, mid-back, lower arms, lower back, and buttocks compared to male agricultural workers, with very high significance differences. Male agricultural workers felt Musculoskeletal Disorders in the thighs and legs. 
Table 5. Musculoskeletal disorders

\begin{tabular}{|l|c|c|c|c|c|c|c|}
\hline \multirow{2}{*}{$\begin{array}{l}\text { Sl. } \\
\text { No. }\end{array}$} & \multirow{2}{*}{ Body pain } & \multicolumn{2}{|c|}{ Male } & \multicolumn{2}{c|}{ Female } & \multirow{2}{*}{ T } & \multirow{2}{*}{ P } \\
\cline { 3 - 6 } & & Mean & SD & Mean & SD & & \\
\hline 1. & Neck & 0.74 & 0.43 & 0.77 & 0.41 & 0.47 & 0.34 \\
\hline 2. & Shoulders & 0.58 & 0.49 & 0.68 & 0.46 & 1.30 & 0.14 \\
\hline 3. & Upper-back & 0.68 & 0.46 & 0.98 & 0.11 & 5.40 & $0.00^{* *}$ \\
\hline 4. & Upper arms & 0.52 & 0.50 & 0.73 & 0.44 & 2.71 & $0.00^{* *}$ \\
\hline 5. & Mid back & 0.78 & 0.41 & 1.00 & 0.00 & 4.54 & $0.00^{* *}$ \\
\hline 6. & Lower arms & 0.54 & 0.50 & 0.69 & 0.46 & 1.99 & $0.01^{* *}$ \\
\hline 7. & Lower Back & 0.94 & 0.22 & 0.97 & 0.16 & 2.07 & $0.00^{* *}$ \\
\hline 8. & Buttocks & 0.12 & 0.32 & 0.23 & 0.42 & 1.84 & $0.00^{* *}$ \\
\hline 9. & Thigh & 0.60 & 0.49 & 0.55 & 0.50 & 0.68 & 0.19 \\
\hline 10. & Legs & 0.75 & 0.43 & 0.73 & 0.44 & 0.27 & 0.57 \\
\hline
\end{tabular}

$(\mathrm{M}=$ Mean, S.D. $=$ Standard Deviation $),{ }^{\star}$ Significant $\mathrm{P}<0.05$,

**highly significant $\mathrm{P}<0.01$

The data shows that female agricultural workers had more neck pain $(\mu=0.77)$ compared to male agricultural workers during working in the field. Female agricultural workers had more pain $(\mu=0.68)$ as compared to male agricultural workers in the shoulders. The female agricultural workers worked in the fields for long periods in leaning postures due to which they had to face more pain $(\mu=0.98)$ in the upper back as compared to male agricultural workers. Female agricultural workers suffered more $(\mu=0.73)$ pain in the upper arms area as compared to male agricultural workers. More pain $(\mu=1.00)$ in the mid-back was reported by the female agricultural workers as compared to male agricultural workers. Lower arm pain was found to be higher $(\mu=0.69)$ in female agricultural workers compared to male agricultural workers. Female agricultural workers experienced severe lower back pain $(\mu=0.97)$, and male agricultural workers had less pain as compared to female agricultural workers. Female agricultural workers felt more pain $(\mu=0.23)$ in buttocks compared to male agricultural workers. Male agricultural workers felt more pain in the thighs $(\mu=0.60)$ and legs $(\mu=0.75)$, in comparison to female agricultural workers.

\subsection{Musculoskeletal Disorders According to Working Hours}

The data of Table 6 depicted that maximum body discomfort was felt by the respondents whose working period was more than 10 hours. Pain in shoulders $(\mu=1.00)$ followed by upper back $(\mu=1.00)$, upper arms $(\mu=1.00)$ was found to be maximum in workers whose work duration was more than 10 hours. Equal intensity $(\mu=1.00)$ of pain was found in the mid back and lower arms among the workers whose working hours was 10-12 hours. In contrary pain in neck $(\mu=0.69)$ was expressed by the workers whose work duration was 6-8 hours.
Table 6. Musculoskeletal disorders according to working hours

\begin{tabular}{|c|c|c|c|c|c|c|}
\hline \multirow{3}{*}{$\begin{array}{l}\text { Sl. } \\
\text { No. }\end{array}$} & \multirow[t]{3}{*}{ Body pain } & \multicolumn{3}{|c|}{ Working hours } & \multirow[t]{3}{*}{ F } & \multirow[t]{3}{*}{$\mathbf{P}$} \\
\hline & & $M \pm$ S.D. & M \pm S.D. & M. \pm S.D. & & \\
\hline & & 6-8 hours & $\begin{array}{c}8-10 \\
\text { hours }\end{array}$ & $\begin{array}{l}10-12 \\
\text { hours }\end{array}$ & & \\
\hline 1. & Neck & $0.69 \pm 0.46$ & $0.42 \pm .048$ & $0.00 \pm 0.00$ & 2.89 & $0.05^{\star}$ \\
\hline 2. & Shoulders & $0.35 \pm 0.48$ & $0.80 \pm 0.40$ & $1.00 \pm 0.00$ & 24.24 & $0.00^{* *}$ \\
\hline 3. & Upper back & $0.66 \pm 0.47$ & $0.96 \pm 0.19$ & $1.00 \pm 0.00$ & 14.87 & $0.00^{* *}$ \\
\hline 4. & Upper arms & $0.50 \pm 0.50$ & $0.68 \pm 0.46$ & $1.00 \pm 0.00$ & 6.96 & $0.00^{* *}$ \\
\hline 5. & Mid back & $0.74 \pm 0.44$ & $1.00 \pm 0.00$ & $1.00 \pm 0.00$ & 14.99 & $0.00^{* *}$ \\
\hline 6. & Lower arms & $0.58 \pm 0.49$ & $0.58 \pm 0.49$ & $1.00 \pm 0.00$ & 4.54 & $0.01^{* *}$ \\
\hline 7. & Lower Back & $0.96 \pm 0.17$ & $0.97 \pm 0.16$ & $1.00 \pm 0.00$ & 0.21 & 0.80 \\
\hline 8. & Buttocks & $0.12 \pm 0.33$ & $0.17 \pm 0.38$ & $0.46 \pm 0.51$ & 4.19 & $0.01^{\star *}$ \\
\hline 9. & Thigh & $0.54 \pm 0.50$ & $0.54 \pm 0.50$ & $0.91 \pm 0.07$ & 3.53 & $0.03^{* *}$ \\
\hline 10. & Legs & $0.70 \pm 0.45$ & $0.74 \pm 0.43$ & $0.92 \pm 0.27$ & 1.29 & 0.27 \\
\hline
\end{tabular}

$(\mathrm{M}=$ Mean, $\mathrm{S} . \mathrm{D} .=$ Standard Deviation $),{ }^{\star}$ Significant $\mathrm{P}<0.05$,

**highly significant $\mathrm{P}<0.01$

It was found that almost equal intensity of pain in lower back $(\mu=1.00)$ was found among the workers whose work duration was more than 10 hours. A clear evidence of body pain in buttocks $(\mu=0.46)$ and thigh $(\mu=0.91)$ was found among those workers whose working hours was 10-12 hours. Pain in legs $(\mu=0.92)$ was also found maximum in those workers who spent 10-12 hours in the field. Highly significant differences were found in the appearance of musculoskeletal disorders in the workers working for 6-8 and 10-12 hours.

\section{Conclusion}

Agriculture plays a very important role in the economy of India. About $70 \%$ of people live their life by relying on agriculture. The credit goes to the agricultural workers who work hard day and night in the sun, rain, and cold sometimes. They help to make food easily available for us to eat. Agricultural workers suffer more pain in the upper back, upper arms, mid-back, lower arms, lower back, and buttocks. Female agricultural workers suffer more pain as compared to male agricultural workers. Female agricultural workers have to face more pain because they work for long hours. Female agricultural workers work longer hours as compared to male agricultural workers. Proper training programs should be organized for prevention. Agricultural workers should be given proper information about musculoskeletal disorders, so that they can get help in identifying the symptoms. Through the programs, they should be provided complete information about precautions to be taken while doing the work. Quality of life of agricultural workers has to be improved through providing proper work 
environment, training programmes on use of agricultural tools and appliances.

\section{References}

1. Kolstrup CL. Work-related musculoskeletal discomfort of dairy farmers and employed workers. Journal of Occupational Medicine and Toxicology. 2012. http://www.occup-med.com/ content/7/1/23. https://doi.org/10.1186/1745-6673-7-23. PMid:23152974 PMCid:PMC3534013.

2. Kolstrup C, Stal M, Pinzke S, Lundqvist P. Ache, pain, and discomfort: The reward for working with many cows and sows? Journal of Agromedicine. 2006; 11(2). https://doi.org/10.1300/ J096v11n02_08. PMid:17135142.

3. Holmberg S, Stiernstrom M, Thelin A, Svardsudd K. Musculoskeletal symptoms among farmers and non-farmers. International Journal Occupation Environment Health. 2002; 8. https://doi.org/10.1179/oeh.2002.8.4.339. PMid:12412852.

4. Gadhavi B, Shukla Y. Prevalence of work related musculoskeletal disorders in farmers of Gujarat. International Journal of Research and Review. 2019; 6(11).

5. Mokamelkhah EK, Aghilinejad M, Ahmadi AB, Abbaszadeh S, Moslemi S, Shahnaghi N, Nassiri-kashani MH. Role of farming in development risk of musculoskeletal disorders among rice farmers: A Prospective study. Iranian Journal of Health, Safety and Environment, 2015; 3.

6. Osborne A, Blake C, Namara JM, Meredith D, Phelan J, Cunningham C. Musculoskeletal disorders among Irish farmers. Society of Occupational Medicine. 2010; 60. https://doi. org/10.1093/occmed/kqq146. PMid:20844056.

7. Gupta G, Tarique. Prevalence of musculoskeletal disorders in farmers of Kanpur-Rural, India. Journal Community Med Health Education. 2013; 3(7). http://dx.doi.org/10.4172/21610711.1000249 .
8. David GC. Ergonomic methods for assessing exposure to risk factors for work-related musculoskeletal disorders. Occupational Medicine. 2005; 55. https://doi.org/10.1093/occmed/kqi082. PMid:15857898.

9. Davis KG, Kotowski SE. Understanding the ergonomic risk for musculoskeletal disorders in the United States Agricultural Sector. American Journal of Industrial Medicine. 2007. https:// doi.org/10.1002/ajim.20479. PMid:17506508.

10. Osborne A, Blake C, Fullen BM, Meredith D, Phelan J, McNamara J, Cunningham C. Prevalence of musculoskeletal disorders among farmers: A systematic review. Journal of Industrial Medicine. 2012. https://doi.org/10.1002/ajim.2103.

11. Nopkesorn T, Pannarunothi S. Prevalence of low back pain among rice farmers: A systematic review. American. 2011; 94(5).

12. Omran A, Reza G, Shamsedin AS, Yahya R, Pouria SD. Prevalence of musculoskeletal disorders among farmers in Eastern Azerbaijan, Iran. Indian Journal of Science and Technology. 2015; 8(28). https://doi.org/10.17485/ijst/2015/v8i28/83330.

13. Naeini HS. Karuppiah K, Tamrin SB, Dalal K. Ergonomics in agriculture: An approach in prevention of Work-related Musculoskeletal Disorders (WMSDs). Journal of Agriculture and Environmental Sciences. 2014; 3.

14. Devi K, Kiran UV. Work related musculoskeletal disorders among workers in unorganized sector. International Journal of Technical Research and Applications. 2015; 3.

15. Srivastava S, Kiran UV. Work related musculoskeletal disorder on various body segments in taxi drivers. International Journal of Science and Research (IJSR). 2014; 3(6).

16. Kumari S, Kiran UV. Musculoskeletal disorders among rag pickers at Lucknow City. Journal of Ecophysiology and Occupational Health. 2020; 20(3\&4). https://doi.org/10.18311/ jeoh/2020/25378.

17. Corlett, E. N. and Bishop, R. P. (1976) A technique for measuring postural discomfort. https://www.Humanics-es.com 